\title{
Central Vasopressin VIA Receptor Blockade Impedes Hypothalamic-Pituitary-Adrenal Habituation to Repeated Restraint Stress Exposure in Adult Male Rats
}

\author{
Megan Gray', Leyla Innala' and Victor Viau*,' \\ 'Neuroscience Program, Department of Cellular and Physiological Sciences, Life Science Centre, University of British Columbia, \\ Vancouver, British Columbia, Canada
}

\begin{abstract}
Previous studies suggest that central arginine vasopressin (AVP) signaling can inhibit the hypothalamic-pituitary-adrenal (HPA) axis. To test a role for the AVP $\vee I A$ receptor in stress HPA axis habituation, adult male rats were exposed to 5 consecutive days of $3 \mathrm{~h}$ restraint with or without continuous intracerebroventricular infusion of the $\mathrm{VIA}$ receptor antagonist $\mathrm{d}(\mathrm{CH} 2) 5 \mathrm{Tyr}(\mathrm{Me}) \mathrm{AVP}(\mathrm{IO} \mu \mathrm{g} / \mathrm{day})$. Assessment of neuropeptide expression and HPA output under basal conditions revealed no effects of VIA receptor antagonism in stress naive animals. Between the first and last day of restraint exposure, controls showed marked declines in ACTH and corticosterone responses, and maintained plasma concentrations of testosterone. In contrast, VIA receptor antagonized animals displayed significantly smaller declines in ACTH and corticosterone responses, and a decrease in plasma testosterone. Despite their reduced expression of HPA axis habituation, antagonized animals continued to show stress-induced increases in AVP mRNA in the hypothalamic paraventricular nucleus and bed nucleus of the stria terminalis, and even higher levels of AVP expression in the medial amygdala relative to controls. The data leave open the nature and extent to which these and other AVP-containing pathways are recruited during repeated restraint, but nevertheless reveal a critical role for central VIA receptors in stress adaptation. As the effects of $\mathrm{VIA}$ receptor antagonism were restricted to the repeated restraint condition, we conclude that normal adaptation to stress involves a shift toward enhanced AVP utilization and/or VIA receptor signaling.

Neuropsychopharmacology (2012) 37, 27I2-2719; doi:10.1038/npp.2012.136; published online 25 July 2012
\end{abstract}

Keywords: arginine vasopressin; VIA receptor; bed nucleus of the stria terminalis; medial amygdala; paraventricular nucleus of the hypothalamus; HPA axis

\section{INTRODUCTION}

Glucocorticoids (cortisol in humans, corticosterone in the rat) are important for survival as they regulate essential physiological responses during real (physical or predatory) and perceived (anticipated or emotional) threats to homeostasis. Glucocorticoids promote homeostasis by reallocating energy resources to support bodily functions of immediate priority such as increased glucose mobilization, cardiovascular tone, and cognitive functioning, while temporarily suppressing immune, reproductive, and metabolic systems (de Kloet et al, 2005). Although adaptive in the short term, the detrimental effects of sustained glucocorticoid elevations are readily observed in several affective and metabolic disorders that show overlapping symptomatology including

*Correspondence: Dr V Viau, Neuroscience Program, Department of Cellular and Physiological Sciences, Life Sciences Centre, University of British Columbia, 2350 Health Sciences Mall, Vancouver, BC, Canada V6T IZ3, Tel: + | 604822 3899, Fax: + I 604822 2316,

E-mail: viau@mail.ubc.ca

Received 30 March 2012; revised 6 June 2012; accepted 27 June 2012 immune, neurological, and physiological disturbances (Chrousos, 2009; Radley et al, 2011; Tamashiro et al, 2011).

Equally important for survival is the effective termination or attenuation of hypothalamic-pituitary-adrenal (HPA) axis responses once a threat is removed. Studies in humans and rats have shown that when exposure to the same stimulus is repeated in a predictable manner, the magnitude of glucocorticoid responses readily decreases or habituates during successive bouts (Kirschbaum et al, 1995). As this process is stimulus specific, habituation is thought to be adaptive by minimizing glucocorticoid exposure while maintaining HPA responses to new or unanticipated challenges. Several brain regions and multiple neuropeptide systems, including arginine vasopressin (AVP), have been implicated in mediating chronic stress-induced changes in behavioral, autonomic, and endocrine responses (Herbert, 1993). However, relatively few studies have attempted to systematically link these systems to adaptive responses and normal HPA axis habituation.

AVP regulation of the HPA axis is coordinated by two G protein-coupled receptors, the V1A and V1B subtypes. V1A 
receptors show a widespread distribution within the brain (Ostrowski et al, 1994), whereas V1B receptors are less prominent centrally, but are highly expressed within the anterior pituitary (Vaccari et al, 1998). CRH-producing neurons of the hypothalamic paraventricular nucleus (PVN) coexpress AVP, which potentiates the stimulatory effect of $\mathrm{CRH}$ on ACTH secretion in pituitary corticotropes (Aguilera et $a l, 2008)$. Opposite to the stimulatory actions of V1B receptors on ACTH secretion, however, there is evidence to suggest that the central activation of V1A receptors can inhibit the HPA axis. Injections of a V1A receptor antagonist into the vicinity of the PVN and supraoptic nucleus potentiate circadian- and social stress-induced elevations in HPA axis responses (Kalsbeek et al, 2002; Wotjak et al, 1996). Repeated restraint-induced declines in HPA output are associated with increased numbers of AVP-positive cells and/or higher AVP mRNA expression within the medial amygdala (MeA) and posterior bed nuclei of the stria terminalis (BST) (Gomez et al, 2004; Gray et al, 2010). AVP circuits involving these extrahypothalamic nuclei target a variety of V1A receptor expressing cell groups, including brain regions and hypothalamic relays that are in a position to inhibit HPA effector neurons of the PVN. On the basis of these negative relations between central AVP and HPA responses, we hypothesize that the $\mathrm{V} 1 \mathrm{~A}$ receptor may contribute to the expression of stress HPA axis habituation.

To test this possibility, here we examined the effects of $\mathrm{V} 1 \mathrm{~A}$ receptor antagonism on central and peripheral indices of HPA axis activity in response to intermittent episodes of $3 \mathrm{~h}$ restraint, repeated daily for 5 consecutive days. An intracerebroventricular approach for antagonist delivery was chosen based on the widespread distribution of vasopressincontaining projections and V1A receptors, and to avoid any confounding influence of repeated drug injections. Stressdependent differences in neuroendocrine responses are associated with changes in AVP expression and/or release within the PVN, suprachiasmatic, and supraoptic nuclei (Kalsbeek et al, 1992; Wotjak et al, 2002). Thus, in addition to extrahypothalamic AVP, we assessed whether these nuclei are also recruited to show changes in AVP mRNA expression. As extrahypothalamic AVP is sensitive to variations in both adrenal and gonadal status, treatment and stress effects on testosterone in circulation were also explored.

\section{MATERIALS AND METHODS}

\section{Animals}

Adult male Sprague-Dawley rats (Charles River, Canada) were used, weighing 250-260 g on arrival (50 days old). Rats were pair housed under controlled temperature $\left(23 \pm 2{ }^{\circ} \mathrm{C}\right)$ and lighting conditions (12:12-h light:dark cycle, lights on at 0700 hours) with food and water available ad libitum. Commencing 14 days after arrival, restraint was performed for 5 consecutive days using Plexiglass restrainers for $3 \mathrm{~h}$ each day (0900-1200 hours). All protocols were approved by the University of British Columbia Animal Care Committee.

\section{Surgery and Treatment}

Rats were anesthetized and implanted with Alzet osmotic (model 2004) minipumps (Cupertino, CA), designed to deliver vehicle (saline) or d(CH2)5Tyr(Me)AVP (10 $\mu \mathrm{g} /$ day, Sigma V2255) into the right lateral ventricle using the following stereotaxic coordinates: anteroposterior, $-0.40 \mathrm{~mm}$ from bregma; mediolateral, $+0.50 \mathrm{~mm}$; dorsoventral, $-4.50 \mathrm{~mm}$ from skull. Sham controls followed the same surgical procedures, but without pump implantation. All animals received continuous infusion of vehicle or drug for 7 days before the first episode of restraint to provide appropriate surgical recovery, and to ensure adequate drug delivery before testing. Separate cohorts of stress naive animals, including surgical shams, vehicle- and drug-treated animals were handled daily, but never restrained. Evans Blue dye $(50 \mu \mathrm{l}, 0.02 \%)$ was injected into indwelling cannula at the time of perfusion to assess dye penetration and cannula patency. Animals showing evidence of improper placement or blocked cannula were removed from analysis. Final endocrine analysis included sham $(n=8)$, vehicle $(n=11)$, and antagonist $(n=14)$ group sizes. Subsets of tissue from unstressed animals $(n=7)$ and those exposed to repeated restraint $(n=7)$ were randomly selected for subsequent hybridization-histochemical analysis.

\section{Blood Sampling and Tissue Collection}

Blood samples $(300 \mu \mathrm{l})$ obtained from the tail vein were collected in ice-chilled tubes containing aprotinin and EDTA, then centrifuged at 10000 r.p.m. for $20 \mathrm{~min}$ at $4{ }^{\circ} \mathrm{C}$. Blood samples on the first and last (fifth) day of restraint were obtained from individual animals immediately following home cage removal ( $0 \mathrm{~min})$, and at 30,60, and $90 \mathrm{~min}$ from restraint onset. This sampling interval is optimal for minimizing blood-sampling load and sufficient for detecting stress-induced changes in HPA responses (Gray et al, 2010). To test for possible drug effects on circadian HPA tone, a separate set of unstressed vehicle- and antagonisttreated animals ( $n=6$ per group) were sampled for 5 consecutive days, $2 \mathrm{~h}$ after lights on (0900 hours, light phase) and $2 \mathrm{~h}$ after lights off (2100 hours, dark phase).

\section{Radioimmunoassays}

Plasma hormone concentrations were measured using commercial RIA kits (MP Biomedicals, OH) with [ $\left.\mathrm{I}^{125}\right]$ as tracer, as previously described (Gray et al, 2010). The standard curve $\mathrm{ED}_{50}$ for $\mathrm{ACTH}$, corticosterone, and testosterone was $83.65 \mathrm{pg} / \mathrm{ml}, 166.9 \mathrm{ng} / \mathrm{ml}$, and $0.688 \mathrm{ng} / \mathrm{ml}$, with detection limits of $7.9 \mathrm{pg} / \mathrm{ml}, 6.42 \mathrm{ng} / \mathrm{ml}$, and $0.1 \mathrm{ng} / \mathrm{ml}$, respectively. The intra- and inter-assay coefficients of variation for these assays ranged from $1 \%$ to $7 \%$ and $2 \%$ to $13 \%$, respectively.

\section{Hybridization Histochemistry}

To explore stress and drug interactions on neuropeptide expression, rats were anesthetized for perfusion using a lethal dose of chloral hydrate $(700 \mathrm{mg} / \mathrm{kg}), 24 \mathrm{~h}$ after the last restraint exposure or after an identical number of postsurgical days in unstressed animals. In situ hybridization was performed using ${ }^{33} \mathrm{P}$-labeled antisense cRNA probes as previously described (Gray et al, 2010). The AVP probe was transcribed from a 230-bp cDNA fragment encoding the vasopressin-specific $3^{\prime}$ end of AVP, and the $\mathrm{CRH}$ probe 
from a full-length $(1.2 \mathrm{~kb})$ cDNA encoding mRNA. Based on the strength of autoradiographic signal on X-ray film (Amersham), hybridized slides were coated with autoradiographic emulsion and exposed for: 5, 25, and 27 days for AVP mRNA in the hypothalamus, posterior BST, and MeA, respectively; and 9 days for CRH mRNA in the PVN. Semiquantitative densitometric analysis of relative levels of AVP and CRH mRNA were performed under dark-field illumination of emulsion-coated slides. Optical densities were determined bilaterally on regularly spaced $150 \mu \mathrm{m}$ intervals through each region of interest, and corrected by background subtraction. AVP neurons are widely dispersed through the extent of the MeA and posterior BST. This enabled a more discrete analysis of AVP expression within these regions by counting the number of individual AVP mRNA-positive cells identified as showing silver grain clusters of five times background or greater (Viau et al, 2001). Dark-field images were captured using a Retiga 1300 CCD digital camera (Q-imaging, BC), analyzed using Openlab Image Improvision v.3.0.9 (Quorum Technologies, ON) and ImageJ v.1.38 software (NIH, Bethesda, MD), then exported to Adobe Photoshop (v.10.0) for final figure assembly.

\section{Statistics}

Grouped data from hybridization analyses were compared using two-way ANOVAs for stress (no stress, repeated restraint) and treatment (sham, vehicle, and drug). Threeway ANOVAs (between treatment, within subject) were used to analyze hormone responses using stress (acute, repeat restraint) and time as repeated measures. To gauge relative treatment effects on habituation, total hormone responses (area under the curve) on the last day of restraint, were calculated as a percentage of hormone responses on the first day of restraint within individual animals and compared using one-way ANOVA. Three-way ANOVAs (between treatment, within subject) were used to analyze the diurnal rhythm in basal HPA activity using day of sampling and cycle phase as repeated measures. When appropriate, post hoc comparisons were made using Newman-Keuls.

\section{RESULTS}

\section{Hormone Responses to Restraint}

ACTH and corticosterone. The time course for ACTH and corticosterone responses to acute and repeated restraint are shown in Figures 1a and b, respectively. Significant threeway (treatment $\times$ stress $\times$ time) interactions were revealed for ACTH $(\mathrm{F}(6,90)=5.26 ; P=0.0001)$ and corticosterone (F $(6,90)=6.15 ; P<0.0001)$. ACTH and corticosterone responses did not vary as a function of treatment status during initial restraint exposure (Figures $1 \mathrm{a}$ and $\mathrm{b}$, left). Post hoc analysis confirmed higher ACTH and corticosterone responses in V1A antagonized animals compared with sham and vehicle control groups on the last day of restraint at 30,60, and $90 \mathrm{~min}$ of restraint exposure (Figures $1 \mathrm{a}$ and $\mathrm{b}$, right). Between acute and repeat stress conditions, withingroup comparisons of ACTH responses revealed greater declines in sham and vehicle control groups compared with V1A antagonized animals at 30, 60, and 90 min of restraint
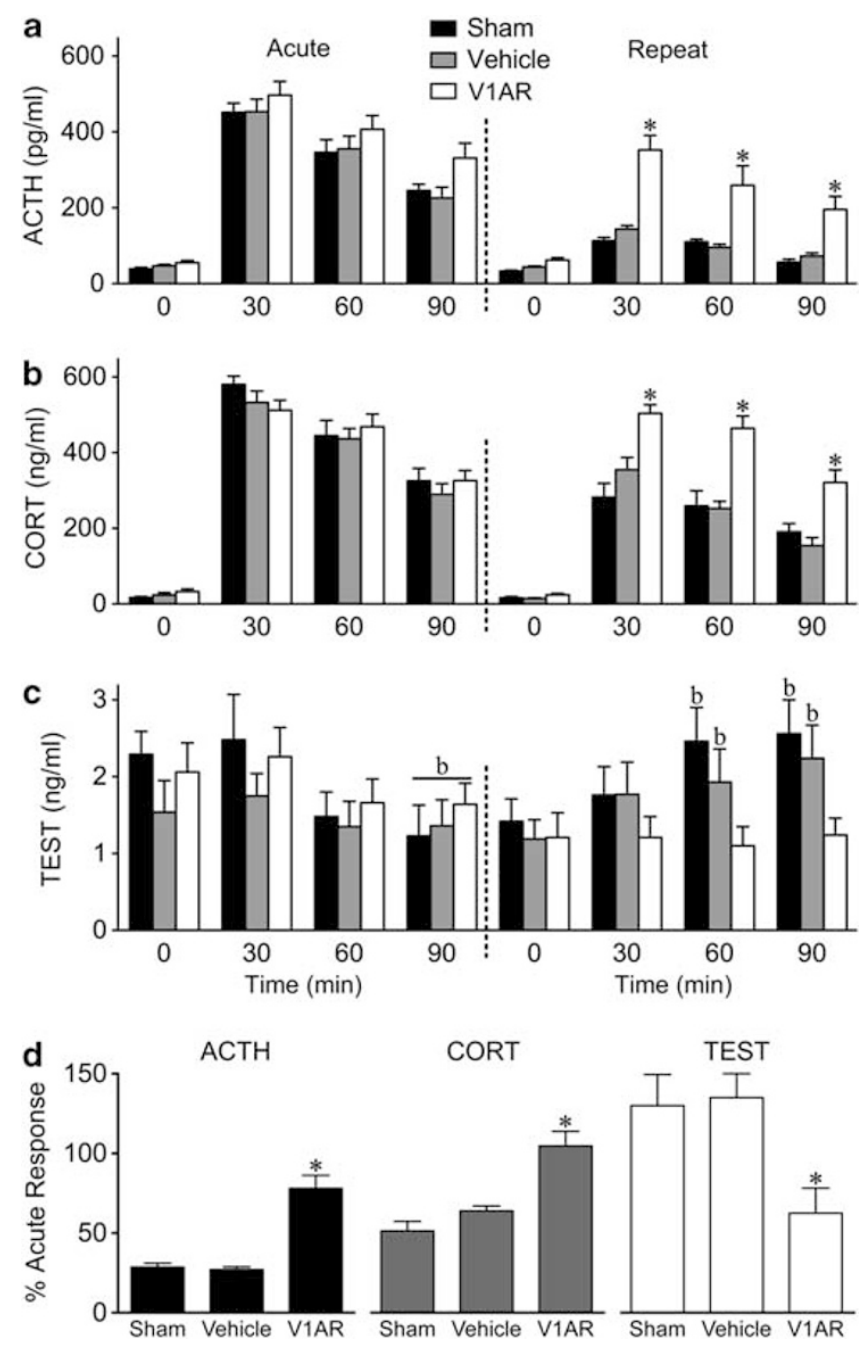

Figure I Mean + SEM ACTH (a), corticosterone (b), and testosterone (c) responses during the first (acute) and last day (repeat) of restraint exposure in surgical sham $(n=8)$, vehicle treated $(n=\mid \mathrm{I})$, and VIA receptor antagonized $(n=14)$ animals. ${ }^{b} P<0.05$ vs basal (time 0$)$; $* P<0.05$ vs sham and vehicle groups on the last day of restraint. Total ACTH, corticosterone, and testosterone responses (d) on the last day as a percentage of total hormone responses on the first day of restraint in surgical sham $(n=8)$, vehicle treated $(n=\mid I)$, and VIA receptor antagonized $(n=14)$ animals. $* P<0.05$ vs sham and vehicle groups.

exposure $(P<0.05$ in all cases). Relative to both control groups, V1A antagonized animals failed to show reliable declines in corticosterone responses ( $P>0.05$ in all cases).

Testosterone. The time course for testosterone responses to acute and repeated restraint is shown in Figure 1c. There was no main effect of treatment $(\mathrm{F}(2,30)=0.52 ; P=0.59)$, but there were significant stress $\times$ time $(\mathrm{F}(3,90)=11.92$; $P<0.0001) \quad$ and treatment $\times$ stress $\quad(\mathrm{F} \quad(2,30)=5.01$; $P=0.013)$ interactions, and a tendency for a three-way (treatment $\times$ stress $\times$ time $)$ interaction $(F \quad(6,90)=1.89$; $P=0.09)$. These interactions were credited, in part, to a general decline in plasma testosterone concentrations between 0 and $90 \mathrm{~min}$ of exposure on the first day of restraint (Figure 1c, left). In contrast, post hoc analysis confirmed significant increases in plasma testosterone at 60 

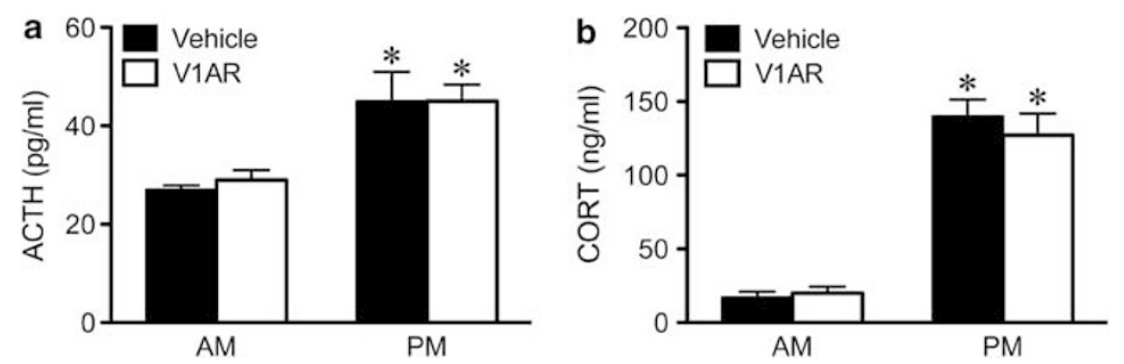

Figure 2 Mean + SEM plasma ACTH (a) and corticosterone (b) concentrations averaged over 5 consecutive days of sampling in the AM and PM phases of the cycle in vehicle treated $(n=6)$ and $V I A$ receptor antagonized $(n=6)$ animals. $* P<0.05$ vs AM.

and 90 min of exposure in sham and vehicle control groups on the last day of restraint, but not for V1A antagonized animals (Figure 1c, right).

\section{Hormonal Habituation}

To gauge relative neuroendocrine responses to repeated restraint as a function of treatment status, total hormone responses (area under the curve) on the last day were calculated as a percentage of total hormone responses on the first day of restraint (Figure 1d). Significant effects of treatment were revealed for the percent change in ACTH (F $(2,30)=18.47 ; P<0.0001)$, corticosterone $(\mathrm{F}(2,30)=21.25$; $P<0.0001)$, and testosterone $(\mathrm{F}(2,30)=3.61 ; P=0.039)$. Post hoc analysis confirmed greater relative declines in total ACTH and corticosterone responses in sham- and vehicletreated animals compared with V1A antagonized animals (Figure 1d, left and middle). Testosterone responses remained comparable for sham- and vehicle-treated animals between the first and last day of restraint, whereas V1A antagonized animals showed a relative decline in testosterone (Figure 1d, right).

\section{Basal ACTH and Corticosterone}

For ACTH (Figure 2a), there was a significant effect of cycle phase $(\mathrm{F}(1,40)=31.65 ; P=0.002)$, but no significant effect of treatment $(\mathrm{F}(1,10)=0.61 ; P=0.45)$ and no treatment $\times$ day $\times$ cycle phase interaction $(\mathrm{F}(4,40)=0.15$; $P=0.96$ ). Corticosterone levels (Figure $2 \mathrm{~b}$ ) similarly revealed a significant effect of cycle phase $(\mathrm{F}(1,40)=259.84$; $P<0.0001$ ), no significant effect of treatment (F $(1,10)=0.53 ; P=0.49)$, and no treatment $\times$ day $\times$ cycle phase interaction $(\mathrm{F}(4,40)=0.45 ; P=0.77)$. Post hoc analysis confirmed higher plasma levels of ACTH and corticosterone during the PM phase of the cycle, comparable between vehicle and V1A antagonized animals.

\section{CRH and AVP Expression in the PVN}

Densitometric analysis of relative levels of CRH mRNA in the medial dorsal parvocellular (mpd), anterior pituitaryregulating zone of the PVN (Figure 3e) revealed no significant effects of treatment $(\mathrm{F}(2,41)=0.003 ; P>0.5)$ and stress $(F(1,41)=0.95 ; P=0.34)$, and no significant treatment $\times$ stress interaction $(\mathrm{F} \quad(2,41)=0.84 ; P=0.44)$ between stress naive animals and those exposed to repeated restraint. Using adjacent sections for AVP mRNA detection in the PVNmpd region (Figure 3, middle), there was no significant effect of treatment $(\mathrm{F}(2,41)=0.063 ; P>0.5)$ and no significant treatment $\times$ stress interaction $(\mathrm{F}(2,41)=0.14$; $P>0.5$ ). However, there was a significant effect of stress (F $(1,41)=21.66 ; P<0.001)$, credited to significant increases in AVP mRNA across all groups (Figure 3f). For AVP in the PM division of the PVN, there was no significant effect of stress (F $(1,41)=0.25 ; P>0.5)$ or treatment $(\mathrm{F}(2,41)=0.18$; $P>0.5)$, and no significant treatment $\times$ stress interaction $(\mathrm{F}(2,41)=0.18 ; P>0.5)$ (data not shown).

\section{AVP Expression in the Supraoptic and Suprachiasmatic Nuclei}

Similar to its magnocellular counterpart in the PVN, the supraoptic nucleus showed no significant effect of stress (F $(1,41)=0.06 ; P>0.5)$ or treatment $(\mathrm{F}(2,41)=0.61 ; P>0.5)$, and no significant treatment $\times$ stress interaction (F $(2,41)=0.21 ; P>0.5)$ for AVP mRNA (data not shown). For the suprachiasmatic nucleus (SCN), there was no significant effect of stress (F $(1,41)=0.08 ; P>0.5)$ or treatment (F $(2,41)=0.67 ; P>0.5)$, and no significant treatment $\times$ stress interaction $(\mathrm{F}(2,41)=0.004 ; P>0.5)$ (data not shown).

\section{AVP Expression within Extrahypothalamic Regions}

For AVP cell numbers in the posterior BST (Figure 4, top), there was no significant effect of treatment $(\mathrm{F}(2,41)=0.11$; $P>0.5)$ and no significant treatment $\times$ stress interaction (F $(2,41)=0.20 ; P>0.5)$ between stress naive animals and those exposed to repeated restraint. However, there was a significant effect of stress $(F(1,41)=45.97 ; P<0.001)$, credited to significant increases in the number of cells expressing the AVP transcript across treatment groups (Figure 4e). For the MeA (Figure 4, middle), there were significant effects of treatment $(\mathrm{F}(2,41)=7.25 ; P=0.03)$ and stress $(F(1,41)=67.68 ; P<0.001)$, and a significant treatment $\times$ stress interaction $(\mathrm{F}(2,41)=4.17 ; P=0.025)$. Post hoc analysis confirmed a stimulatory effect of repeated restraint on the number of AVP expressing cells in the MeA, highest in V1A antagonized animals (Figure 4f).

\section{DISCUSSION}

The results of our experiments revealed an effect of V1A receptor antagonism to reduce the normal decline in ACTH and corticosterone responses to repeated restraint, implicating a central role for AVP in stress HPA axis habituation. 

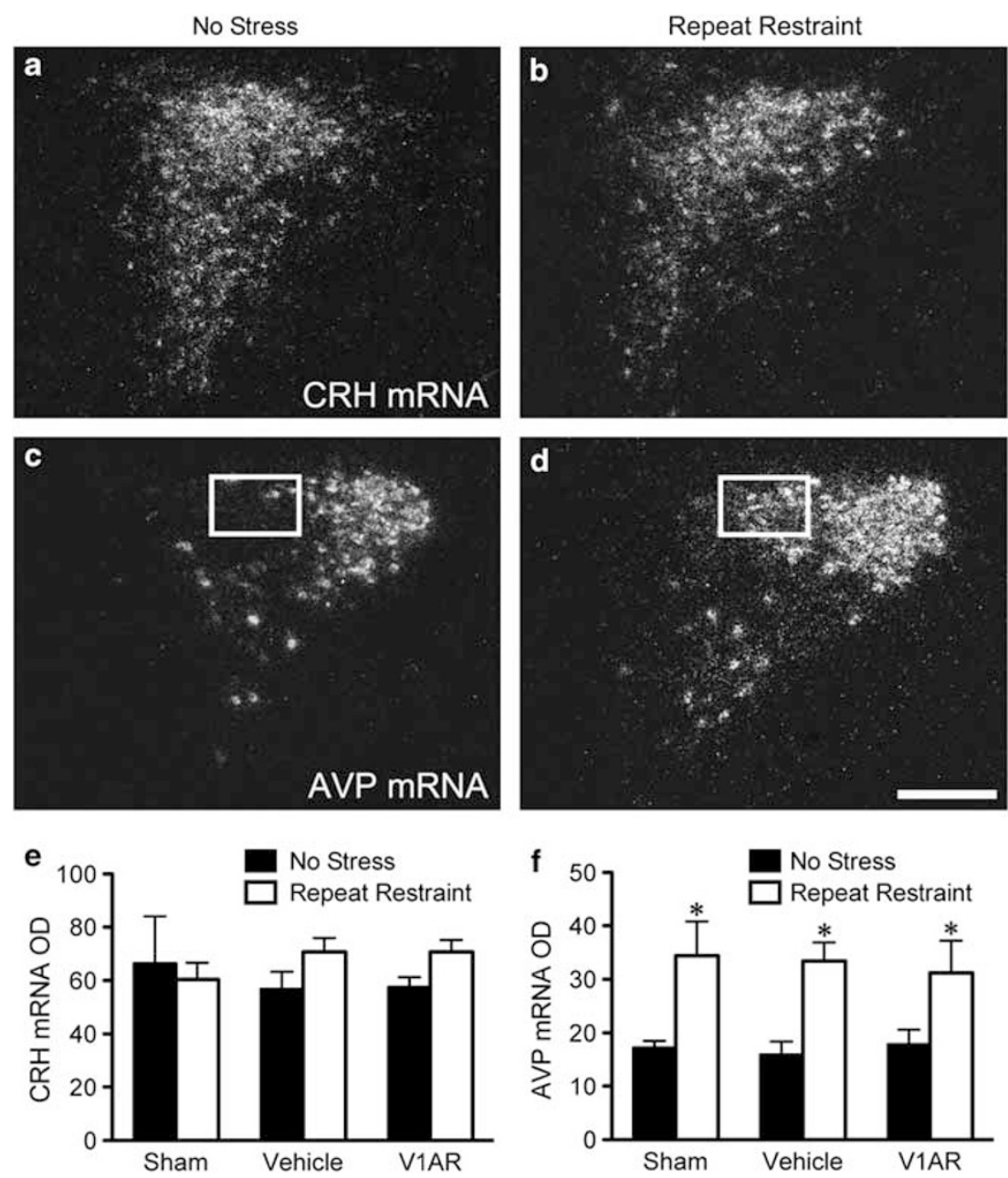

Figure 3 Representative photomicrographs showing the distribution and relative strength of hybridization signal for CRH and AVP mRNA in the PVN under basal conditions in unstressed sham animals (a, c, respectively) and those exposed to repeated restraint (b, d, respectively). Repeated restraint results in a marked increase in AVP, but not CRH expression within the dorsal body of the medial parvocellular (mpd) part of the PVN (boxed region). Scale bar $=200 \mu \mathrm{m}$ (applies to all). Mean + SEM relative optical density (OD) measures levels of CRH (e) and AVP (f) mRNA in the PVNmpd as a function of treatment condition (no stress, repeat restraint) in surgical sham, vehicle-treated, and VIA receptor antagonized animals ( $n=7$ per group). $* P<0.05$ vs unstressed counterparts.

Although the decline in ACTH responses was attenuated in animals bearing continuous infusion of the $\mathrm{V} 1 \mathrm{~A}$ receptor antagonist, the decline in corticosterone was completely prevented. This suggests that V1A receptors may operate within autonomic (sympathoadrenal) cell groups subserving adrenal sensitivity to ACTH, in addition to neuroendocrine responses (Engeland and Arnhold, 2005; Kalsbeek et al, 2012). V1A receptor antagonism had no effect on the magnitude of the HPA response to initial restraint exposure or at the onset of restraint $(0 \mathrm{~min})$ on either the first or last day of restraint. Nevertheless, we wondered whether the observed drug effects might be explained by changes in basal HPA tone, not readily detectable during the circadian trough of activity. A follow-up study using a separate cohort of unstressed animals showed no effect of continuous antagonism on absolute levels and AM-PM phase differences for ACTH and corticosterone. This finding does not rule out a role for AVP in the daily HPA axis rhythm, as elevations in basal corticosterone levels follow intracerebral injections of a V1A antagonist into the DMH (Kalsbeek et al, 2012). Although this discrepancy reflects a limited capacity of the V1A antagonist delivered via the ventricles to access the brain parenchyma, it also raises the possibility that AVP circuits regulating stress may be distinct from those subserving circadian rhythms in the HPA axis. As the effects of V1A receptor antagonism occurred only during repeated restraint, this supports our conclusion that normal adaptation to stress involves a shift toward enhanced AVP utilization and/or V1A receptor signaling.

Analysis of gonadal status provided a physiological readout of the importance of achieving proper HPA axis habituation. Testosterone responses between the first and last day of restraint were effectively maintained in control animals showing HPA axis habituation, but were reduced in $\mathrm{V} 1 \mathrm{~A}$ receptor antagonized animals. Although chronic stress and prolonged elevations in glucocorticoids have been shown to inhibit testosterone secretion and release (Rivier and Rivest, 1991), our previous experiments suggest an underlying drive to the gonadal axis during repeated 

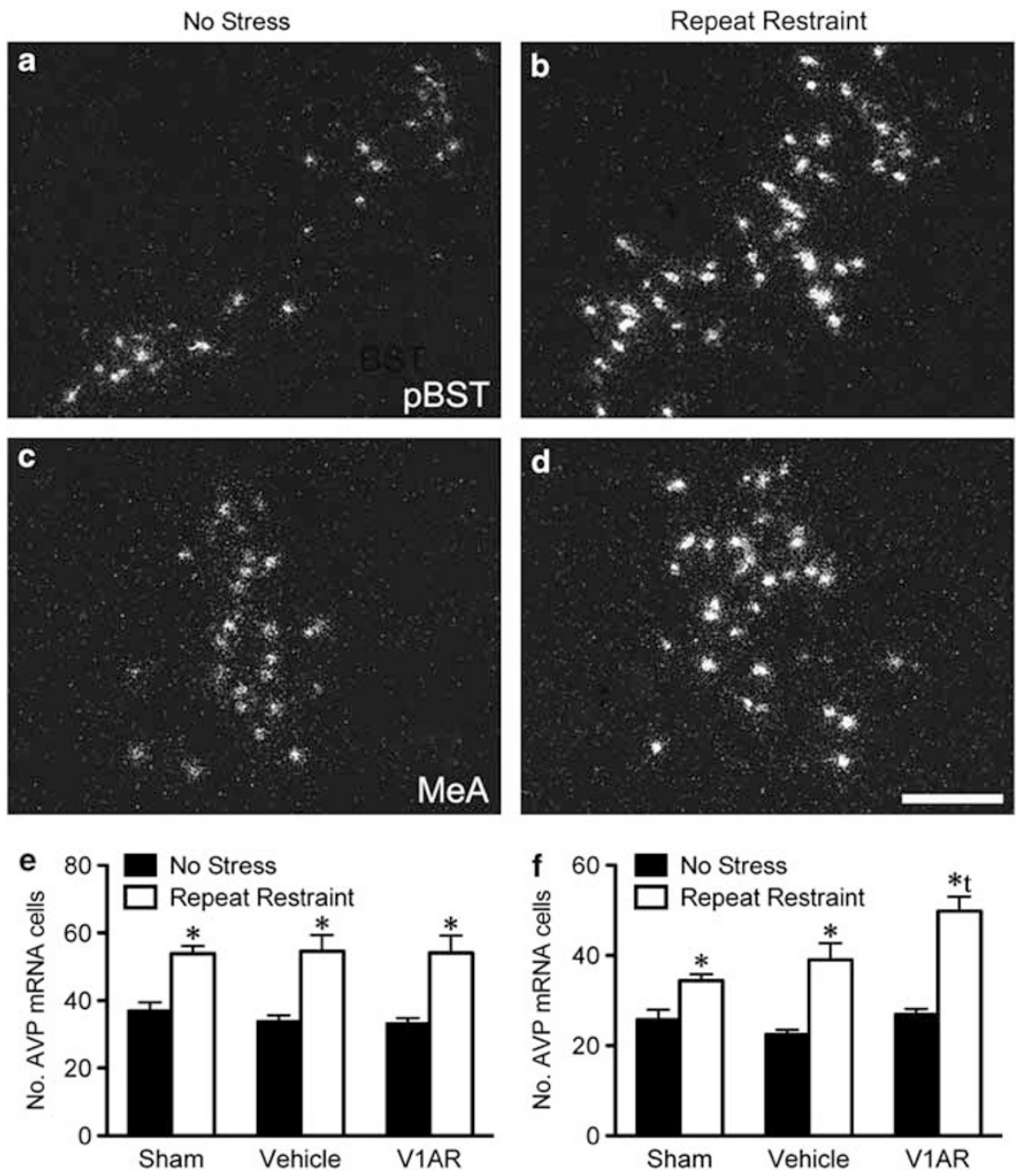

Figure 4 Representative photomicrographs showing the distribution and relative strength of hybridization signal for AVP mRNA within the posterior BST and $\mathrm{MeA}$ under basal conditions in unstressed sham animals (a, c, respectively) and those exposed to repeated restraint (b, d, respectively). Scale bar $=200 \mu \mathrm{m}$ (applies to all). Mean + SEM relative numbers of AVP mRNA expressing cells per $30 \mu \mathrm{m}$ section in the posterior BST (e) and MeA ( $f$ ) as a function of treatment condition (no stress, repeat restraint) in surgical sham, vehicle-treated, and VIA receptor antagonized animals ( $n=7$ per group). The results show that repeated restraint increases AVP mRNA expression within both extrahypothalamic regions, and that $\mathrm{VIA}$ receptor antagonism enhances this effect in the MeA. $* P<0.05$ vs unstressed counterparts; ${ }^{t} P<0.05$ vs repeatedly restrained sham and vehicle groups.

restraint. Whereas gonadal intact male rats display higher numbers of medial preoptic GnRH expressing cells after repeated restraint (Gray et al, 2010), castrated male rats show potentiated luteinizing hormone responses (Bingham et al, 2005). Importantly, this could provide a mechanism of maintaining reproductive capacity in the face of repeated stress, provided proper declines in corticosterone responses occur. Conversely, decreased testosterone responses in V1A antagonized animals may be explained by a reduced drive to the gonadal axis as a result of sustained levels of corticosterone exposure.

All treatment groups showed comparable increases in AVP mRNA within the PVNmpd after repeated restraint, and no change in CRH expression. Increased AVP synthesis and release from PVN neurosecretory neurons is thought to sustain minimal levels of ACTH release by activating V1B receptors on anterior pituitary corticotropes, otherwise inhibited by glucocorticoid-mediated negative feedback mechanisms (Aguilera et al, 2008). Despite showing similar restraint-induced increases in hypophysiotropic AVP mRNA, the nature by which V1A receptors actually alter
ACTH secretagogue synthesis and release to promote the formation $v s$ expression of HPA axis habituation remains unclear. Worthy of pursuit, therefore, is the extent to which these processes are dissociable in animals bearing discontinuous injections of the V1A antagonist during repeated restraint exposure.

Central AVP signaling is not restricted to discrete neuronal pathways, as V1A receptors may also be activated by means of AVP diffusion from several distant release points via the extracellular fluid and the CSF (Leng and Ludwig, 2008). Magnocellular neurons of the PVN, supraoptic and SCN contribute to this diffusion pool, and V1A receptors are expressed in the vicinity of each of these nuclei (Ostrowski et al, 1994). There is also evidence to suggest that the intrahypothalamic release of AVP serves as an autocrine or paracrine signal to inhibit or delimit PVN and HPA responses to stressful stimuli and that this depends on the V1A receptor (Wotjak et al, 1998, 2002; Zelena et al, 2009). Although we found no evidence to indicate that the magnocellular hypothalamic cell groups are recruited to express higher levels of AVP, these nuclei 
should not be discounted as representing important sources of influence during repeated stress exposure.

Testosterone has been shown to increase AVP expression in the brain, but only in AVP cells of the posterior BST and MeA (De Vries and Panzica, 2006). Based on their reduced testosterone responses to repeated restraint, we anticipated V1A antagonized animals to show little to no change in AVP expression within these regions. However, these animals continued to show significant increments in the number of AVP expressing cells in the posterior BST, and even higher levels of induction in the MeA. The functional significance of this finding as it relates to HPA axis habituation remains unresolved, as we have yet to characterize the regional specificity and projection profiles of extrahypothalamic cells identified as showing increases in AVP expression in response to repeated stress and/or V1A antagonism. Adrenalectomy decreases the number of AVP-positive neurons in the MeA, but not in the posterior BST (Viau et al, 2001), to predict a stimulatory influence of corticosterone that may be unique to AVP neurons of the amygdala. Hence, potentiated AVP cell numbers in the MeA may well be a secondary response to increased levels of glucocorticoid exposure in V1A antagonized animals.

Combined immunohistochemical and retrograde tracing experiments have revealed AVP cells in the MeA and posterior BST to project to the lateral septum and hippocampus (Caffé et al, 1987). Electrophysiological and behavioral studies have linked extrahypothalamic AVP projections to processes of memory consolidation and emotional responses that may be considered adaptive in the context of stress habituation (Alescio-Lautier and Soumireu-Mourat, 1998; Urban, 1998). Thus, we anticipate the lateral septum and hippocampus, in the very least, to show elevations in AVP immunoreactivity following repeated restraint exposure. Based on anterograde tracing studies (Canteras et al, 1995), the overall pattern of projections from the MeA and posterior division of the BST indicates that these nuclei are also in a position to regulate neuroendocrine responses through multiple cortical, subcortical, and limbic-related pathways to the PVN (Ring, 2005; Williamson et al, 2005; Ulrich-Lai and Herman, 2009). V1A receptors follow the distribution of most AVPcontaining pathways in the forebrain, including within the septum, BST, amygdala, hippocampus, and entorhinal cortex (Tribollet et al, 1988; Ostrowski et al, 1994). Any one of these projection sites could represent viable targets for the endogenous effects of AVP on HPA responses to repeated restraint.

Animals bearing repeated central injections of AVP show sensitized motor and AVP receptor signaling responses to a subsequent challenge dose of AVP, and these alterations are prevented with V1A receptor antagonism (Poulin et al, 1995). V1A receptors respond positively to glucocorticoids, as adrenalectomy causes a dexamethasone reversible decrease in V1A binding in the septum and BST (Watters et al, 1996). Taken together with our findings, increased AVP utilization and corticosterone exposure during successive bouts of repeated restraint could have a converging influence to increase V1A receptor binding and/or signaling. Future studies using these parameters of interest should prove instrumental for clarifying target neuron specificity and sources of AVP responsible for stress adaptation.
The distribution of $\mathrm{V} 1 \mathrm{~A}$ receptors in the brain indicates that AVP can access a variety of response systems to coordinate metabolic, autonomic, behavioral, and neuroendocrine responses to homeostatic threat. All of these systems are debilitated to overlapping degrees in humans suffering from post-traumatic stress disorder, anxiety, and depression (Frank and Landgraf, 2008). Emerging evidence suggests that individual variations in central AVP release could be a predisposing factor underlying these disorders (Frank and Landgraf, 2008). Prevailing models of neuroendocrine habituation suggest a broad array of circuits and contributing factors (Hill et al, 2010; Grissom and Bhatnagar, 2011), and a variety of mechanisms by which normal declines in HPA output may be achieved (reviewed in Herbert, 1993; Grissom and Bhatnagar, 2009). These would include stimulus-specific changes in inhibitory and stimulatory input to the HPA axis (Girotti et al, 2006), and alterations in glucocorticoid-mediated negative feedback efficacy (Cole et al, 2000). Changes in central AVP signaling during repeated stress could conceivably have an active role in linking several of these processes, and our findings provide several new starting points in pursuit of these possibilities.

\section{ACKNOWLEDGEMENTS}

This study was supported by the Canadian Institutes of Health Research (VV), Canadian Graduate Student Scholarships Doctoral Award from the Canadian Institutes of Health Research (MG), and Michael Smith Foundation for Health Research Senior Scholarship (VV).

\section{DISCLOSURE}

The authors declare no conflict of interest.

\section{REFERENCES}

Aguilera G, Subburaju S, Young S, Chen J (2008). The parvocellular vasopressinergic system and responsiveness of the hypothalamic pituitary adrenal axis during chronic stress. Prog Brain Res 170: 29-39.

Alescio-Lautier B, Soumireu-Mourat B (1998). Role of vasopressin in learning and memory in the hippocampus. Prog Brain Res 119: 501-521.

Bingham B, Lee P, Viau V (2005). Adrenal adaptation to repeated restraint is met by an increased drive to the gonadal axis in the male rat. Proc Annual Meeting of the Society for Neuroscience, Washington, DC (Abstract 637.12).

Caffé AR, van Leeuwen FW, Luiten PG (1987). Vasopressin cells in the medial amygdala of the rat project to the lateral septum and ventral hippocampus. J Comp Neurol 261: 237-252.

Canteras NS, Simerly RB, Swanson LW (1995). Organization of projections from the medial nucleus of the amygdala: a PHAL study in the rat. J Comp Neurol 360: 213-245.

Chrousos GP (2009). Stress and disorders of the stress system. Nat Rev Endocrinol 5: 374-381.

Cole MA, Kalman BA, Pace TW, Topczewski F, Lowrey MJ, Spencer RL (2000). Selective blockade of the mineralocorticoid receptor impairs hypothalamic-pituitary-adrenal axis expression of habituation. J Neuroendocrinol 12: 1034-1042.

de Kloet ER, Joëls M, Holsboer F (2005). Stress and the brain: from adaptation to disease. Nat Rev Neurosci 6: 463-475. 
De Vries GJ, Panzica GC (2006). Sexual differentiation of central vasopressin and vasotocin systems in vertebrates: different mechanisms, similar endpoints. Neuroscience 138: 947-955.

Engeland WC, Arnhold MM (2005). Neural circuitry in the regulation of adrenal corticosterone rhythmicity. Endocrine 28: $325-332$.

Frank E, Landgraf R (2008). The vasopressin system-from antidiuresis to psychopathology. Eur J Pharmacol 583: 226-242.

Girotti M, Pace TW, Gaylord RI, Rubin BA, Herman JP, Spencer RL (2006). Habituation to repeated restraint stress is associated with lack of stress-induced c-fos expression in primary sensory processing areas of the rat brain. Neuroscience 138: 1067-1081.

Gomez F, Manalo S, Dallman MF (2004). Androgen-sensitive changes in regulation of restraint-induced adrenocorticotropin secretion between early and late puberty in male rats. Endocrinology 145: 59-70.

Gray M, Bingham B, Viau V (2010). A comparison of two repeated restraint stress paradigms on hypothalamic-pituitary-adrenal axis habituation, gonadal status and central neuropeptide expression in adult male rats. J Neuroendocrinol 22: 92-101.

Grissom N, Bhatnagar S (2009). Habituation to repeated stress: get used to it. Neurobiol Learn Mem 92: 215-224.

Grissom NM, Bhatnagar S (2011). The basolateral amygdala regulates adaptation to stress via beta-adrenergic receptormediated reductions in phosphorylated extracellular signalregulated kinase. Neuroscience 178: 108-122.

Herbert J (1993). Peptides in the limbic system: neurochemical codes for co-ordinated adaptive responses to behavioural and physiological demand. Prog Neurobiol 41: 723-791.

Hill MN, McLaughlin RJ, Bingham B, Shrestha L, Lee TT, Gray JM et al (2010). Endogenous cannabinoid signaling is essential for stress adaptation. Proc Natl Acad Sci USA 107: 9406-9411.

Kalsbeek A, Buijs RM, van Heerikhuize JJ, Arts M, van der Woude TP (1992). Vasopressin-containing neurons of the suprachiasmatic nuclei inhibit corticosterone release. Brain Res 580: 62-67.

Kalsbeek A, Palm IF, Buijs RM (2002). Central vasopressin systems and steroid hormones. Prog Brain Res 139: 57-73.

Kalsbeek A, van der Spek R, Lei J, Endert E, Buijs RM, Fliers E (2012). Circadian rhythms in the hypothalamo-pituitary-adrenal (HPA) axis. Mol Cell Endocrinol 349: 20-29.

Kirschbaum C, Prussner JC, Stone AA, Federenko I, Gaab J, Lintz $\mathrm{D}$ et al (1995). Persistent high cortisol responses to repeated psychological stress in a subpopulation of healthy men. Psychosom Med 57: 468-474.

Leng G, Ludwig M (2008). Neurotransmitters and peptides: whispered secrets and public announcements. J Physiol 586: $5625-5632$.

Ostrowski NL, Lolait SJ, Young III WS (1994). Cellular localization of vasopressin V1a receptor messenger ribonucleic acid in adult male rat brain, pineal, and brain vasculature. Endocrinology 135: 1511-1528.

Poulin P, Szot P, Dorsa DM, Pittman QJ (1995). Vasopressininduced sensitization: involvement of neurohypophyseal peptide receptors. Eur J Pharmacol 294: 29-39.

Radley JJ, Kabbaj M, Jacobson L, Heydendael W, Yehuda R, Herman JP (2011). Stress risk factors and stress-related pathology: neuroplasticity, epigenetics and endophenotypes. Stress 14: 481-497.

Ring RH (2005). The central vasopressinergic system: examining the opportunities for psychiatric drug development. Curr Pharm Des 11: 205-225.

Rivier C, Rivest S (1991). Effect of stress on the activity of the hypothalamic-pituitary-gonadal axis: peripheral and central mechanisms. Biol Reprod 45: 523-532.

Tamashiro KL, Sakai RR, Shively CA, Karatsoreos IN, Reagan LP (2011). Chronic stress, metabolism, and metabolic syndrome. Stress 14: 468-474.

Tribollet E, Barberis C, Jard S, Dubois-Dauphin M, Dreifuss JJ (1988). Localization and pharmacological characterization of high affinity binding sites for vasopressin and oxytocin in the rat brain by light microscopic autoradiography. Brain Res 442: 105-118.

Ulrich-Lai YM, Herman JP (2009). Neural regulation of endocrine and autonomic stress responses. Nat Rev Neurosci 10: 397-409.

Urban IJA (1998). Effects of vasopressin and related peptides on neurons of the rat lateral septum and ventral hippocampus. Prog Brain Res 119: 285-310.

Vaccari C, Lolait SJ, Ostrowski NL (1998). Comparative distribution of vasopressin $\mathrm{V} 1 \mathrm{~b}$ and oxytocin receptor messenger ribonucleic acids in brain. Endocrinology 139: 5015-5033.

Viau V, Soriano L, Dallman MF (2001). Androgens alter corticotropin releasing hormone and arginine vasopressin mRNA within forebrain sites known to regulate activity in the hypothalamic-pituitary-adrenal axis. J Neuroendocrinol 13: 442-452.

Watters JJ, Wilkinson CW, Dorsa DM (1996). Glucocorticoid regulation of vasopressin V1a receptors in rat forebrain. Brain Res Mol Brain Res 38: 276-284.

Williamson M, Bingham B, Viau V (2005). Central organization of androgen-sensitive pathways to the hypothalamic-pituitaryadrenal axis: implications for individual differences in responses to homeostatic threat and predisposition to disease. Prog Neuropsychopharmacol Biol Psychiatry 29: 1239-1248.

Wotjak CT, Ganster J, Kohl G, Holsboer F, Landgraf R, Engelmann M (1998). Dissociated central and peripheral release of vasopressin, but not oxytocin, in response to repeated swim stress: new insights into the secretory capacities of peptidergic neurons. Neuroscience 85: 1209-1222.

Wotjak CT, Kubota M, Liebsch G, Montkowski A, Holsboer F, Neumann I et al (1996). Release of vasopressin within the rat paraventricular nucleus in response to emotional stress: a novel mechanism of regulating adrenocorticotropic hormone secretion? J Neurosci 16: 7725-7732.

Wotjak CT, Ludwig M, Ebner K, Russell JA, Singewald N, Landgraf $\mathrm{R}$ et al (2002). Vasopressin from hypothalamic magnocellular neurons has opposite actions at the adenohypophysis and in the supraoptic nucleus on ACTH secretion. Eur J Neurosci 16: 477-485.

Zelena D, Langnaese K, Domokos A, Pinter O, Landgraf R, Makara G et al (2009). Vasopressin administration into the paraventricular nucleus normalizes plasma oxytocin and corticosterone levels in Brattleboro rats. Endocrinology 150: 2791-2998. 